\title{
E-cadherin and c-Met expression in actinic cheilits and lip squamous cell carcinoma
}

\author{
Martínez $\mathrm{A}^{1}$, Spencer $\mathrm{ML}^{1}$, Borlando $\mathrm{J}^{2}$, Flores $\mathrm{M}^{3}$, Rojas IG ${ }^{4}$
}

\section{ABSTRACT}

Objective: The aim of this study was to assess epithelial expression of E-cadherin and c-Met in normal lip, in actinic cheilitis and lip squamous cell carcinoma. Study Design: Biopsies of normal lip vermillion ( $N L, n=18)$, actinic cheilitis $(A C, n=37)$, and lip SCC ( $n=22)$ were processed for E-cadherin and c-Met immunodetection. Epithelial and tumor cell expression was scored for each sample considering staining intensity and percentage. Results: E-cadherin expression was significantly reduced in AC and lip SCC as compared to normal lip ( $\mathrm{P}<0.05)$, with a significant reduction in lip SCC as compared to $A C(P=0.003)$. Expression of $c-M e t$ was significantly higher in $A C$ and lip $S C C$ as compared to $N L(P<0.05)$, with a significant increase in lip SCC as compared to AC $(P<0.0001)$. Conclusion: The results showed that epithelial E-cadherin expression is reduced and c-Met expression is increased as lip carcinogenesis progresses, suggesting that these proteins may be useful markers of malignant transformation.

Rev. Clin. Periodoncia Implantol. Rehabil. Oral Vol. 4(3); 122-125, 2011.

Key words: E-cadherin, c-Met, lip carcinogenesis, UV light, actinic cheilitis, lip squamous cell carcinoma.

\section{INTRODUCTION}

Chronic exposure of the lip vermillion to sunlight and/or artificial ultraviolet irradiation (UV) causes actinic cheilitis (AC), a pre-malignant lesion with the potential to develop into invasive lip squamous cell carcinoma (SCC), the most common form of oral cancer ${ }^{(1)}$.

E-cadherin is a calcium-dependent membranous glycoprotein that plays important roles in the maintenance of cell-cell adhesion, preservation of epithelial tissue polarity, and structural integrity ${ }^{(2,3)}$. The inactivation of the E-cadherin cell adhesion system by both genetic and epigenetic mechanisms plays a significant role during multistage human carcinogenesis ${ }^{(3,4)}$. Several studies demonstrate that reduction of E-cadherin expression occurs in oral dysplasia, with such reduction being proportional to the degree of dysplasia( ${ }^{(5-7)}$. E-cadherin expression is frequently down-regulated in a wide variety of human malignancies, including skin cancer ${ }^{(8)}$, oral squamous carcinoma ${ }^{(4,7,9-11)}$, lip $\operatorname{SCC}^{(12)}$, gastric cancer $^{(13,14)}$, breast cancer ${ }^{(15)}$, lung cancer ${ }^{(16)}$, and prostate cancer ${ }^{(17)}$. Reduced E-cadherin expression has been shown to be an indicator of unfavorable prognosis in oral squamous cell carcinoma and in other malignancies ${ }^{(9,10,18)}$

Brouxhon et al. ${ }^{(6)}$ demonstrated that during UV-induced skin carcinogenesis in SKH-1 mice, SCC progression produces a significant and progressive down-regulation of $\mathrm{E}$-cadherin protein expression in epidermal keratinocytes as lesions progress from in situ carcinomas to large invasive SCCs.

The proto-oncogene, c-Met, is a transmembrane tyrosine kinase receptor that mediates the oncogenic activities of the hepatocyte growth factor (HGF). Overexpression of c-Met and/or its ligands has been shown to contribute to progression and dissemination of several malignancies, such as gallbladder ${ }^{(19)}$, gastric ${ }^{(20,21)}$, bladder ${ }^{(22)}$, breast ${ }^{(15)}$, and head and neck cancer ${ }^{(7,18,23,24)}$. The overexpression of c-Met frequently has been correlated with poor prognosis in various cancers ${ }^{(20,22)}$.

Several studies have found an inverse correlation between the expression of HGF/c-Met and membranous E-cadherin expression in human tumors ${ }^{(7,15,18,22)}$. A limited number of studies have investigated E-cadherin expression in lip SCC ${ }^{(12)}$. However, E-cadherin expression in AC has not been determined. In addition, the expression of E-cadherin and c-Met has not yet been studied in normal and photodamaged lips. Thus, the purpose of this study was to assess epithelial expression of E-cadherin and c-Met in normal lip, actinic cheilitis (premalignant lesion), and lip SCC samples.

\section{MATERIALS AND METHODS}

\section{Biopsies}

Biopsies of lower lip vermillion from 37 non-smoking patients with AC (12 women and 25 men, age $22-74$ years, mean $52.4 \pm 14.2$ years) were obtained from the Archives of the Oral Pathology Laboratory, School of Dentistry, University of Concepción; and biopsies of 22 lip SCC $(n=15$ well-differentiated, $n=6$ moderately-differentiated, $n=1$ poorlydifferentiated; 4 women and 18 men, age $35-86$ years, mean $65.7 \pm 12.1$ years) were obtained from the Archives of the Department of Pathology, School of Medicine, University of Concepción. Eighteen normal lip vermillion biopsies (12 women and 6 men, age 22-63 years, mean $40.4 \pm 13.3$ years) were used as controls. Informed consent was obtained from all subjects. This study was approved by the Ethics Committee of the University of Concepción.

All specimens were fixed in $10 \%$ buffered formalin, $\mathrm{pH} 7.4$, and paraffin embedded within 24 hours. Serial sections, $4-\mu \mathrm{m}$ thick, were obtained from the tissue blocks and processed for histopathologic and immunohistochemical analyses.

\section{Immunohistochemical Staining}

Tissue sections were deparaffinized in xylene and rehydrated in graded alcohol. Endogenous peroxidase activity was blocked by incubation in methanol with $3 \%$ hydrogen peroxide for 10 minutes. For antigen retrieval, tissue sections were steamed in EDTA buffer $0.001 \mathrm{M}$ $(\mathrm{pH} 8.0)$ at $96^{\circ} \mathrm{C}$ for 30 minutes. After rinsing in phosphate-buffered saline (PBS), slides were incubated overnight with the monoclonal antibody Mouse E-Cadherin Ab-4 (Clone: NCH-38, dilution 1:100, NeoMarkers Laboratories, Fremont, CA, USA) and anti-c-Met monoclonal antibody (Clone: 3D4, dilution 1:100, Invitrogen, ZYMED Laboratories, Carlsbad, CA, USA). The primary antibody was diluted in Antibody Diluent (ZYMED, Carlsbad, CA, USA). This was followed by incubation with the UltraVision ONE HRP Polymer (LAB VISION, Fremont, CA, USA) for 30 minutes. Sections were then washed in PBS and the reaction was developed with DAB (3.3 diaminobenzidine Mouse/Rabbit Plydetector PDBSBA02A7, Bio $\mathrm{SB})$ for 5 minutes at room temperature. Slides were counterstained with Harris hematoxylin. Positive controls were normal skin for E-cadherin, and a papillary thyroid carcinoma for c-Met. The negative controls consisted of replacing the first antibody with buffer and omitting the primary antibody. Epithelial staining scores for E-cadherin and c-Met were

1. Departments of Oral Pathology. School of Dentistry, College of Medicine. University of Concepción, Chile.

2. Departments of Pathology. School of Dentistry, College of Medicine. University of Concepción, Chile.

3. Departments of Public Health. School of Dentistry, College of Medicine. University of Concepción, Chile.

4. Departments of Oral Surgery. School of Dentistry, College of Medicine. University of Concepción, Chile. 
obtained for each sample by two calibrated observers, based on the combination of staining intensity and extension in each tissue section as previously described ${ }^{(25)}$. For $\mathrm{NL}$ and $\mathrm{AC}$ samples, staining extension was evaluated at the basal, parabasal, and suprabasal epithelial layers of each sample. For lip SCC samples, the markers were evaluated in the tumor cells and in the stroma and defined as the percentage of positive cells/field $(x 40)$. Staining intensity for each marker was recorded as undetectable $(0)$, weak (1), medium (2), or strong (3). Results were expressed as the mean $\pm S D$.

\section{Statistical Analysis}

Data were analyzed with statistical software (SPSS, version 16.0; SPSS, Inc, Chicago, III, USA). Differences between groups were examined using the Mann-Whitney test; differences were considered statistically significant when $\mathrm{P}<0.05$.

\section{RESULTS}

Figure 1 shows representative microphotographs of serial sections from normal lip, AC, and lip SCC biopsies immunostained for E-cadherin and c-Met. Strong membranous E-cadherin staining was found in nearly all the epithelial layers of normal lip, excluding the most superficial cells (Figure 1A). For AC specimens, moderate and weak membranous and non-membranous E-cadherin staining was found in basal, parabasal, and middle spinous cells but not in the superficial layers (Figure 1B). For lip SCC samples, the E-cadherin staining was weaker or lost (Figure 1C). Table 1 shows the cellular localization of E-cadherin expression in NL, AC, and lip SCC samples. E-cadherin expression was significantly reduced in $\mathrm{AC}$ and lip SCC as compared to normal lip $(P<0.05$, Mann-Whitney test), with a significant reduction in lip SCC as compared to $A C(P=0.003)$ (Figure $2 A)$.

Immunohistochemistry showed that c-Met expression in NL was negative or occasionally weak at the basal and parabasal epithelial layers (Figure 1D). Weak positive c-Met staining was observed at basal, parabasal, and suprabasal epithelial layers of AC samples (Figure 1E).

In lip SCC samples c-Met was expressed at the membrane and cytoplasm of tumor cells (Figure 1F). Table 2 presents the cellular localization of C-Met expression in NL, AC, and lip SCC samples. Expression of c-Met was significantly higher in AC and lip SCC as compared to $\mathrm{NL}(\mathrm{P}<0.05$, Mann-Whitney test), with a significant increase in lip SCC as compared to $\mathrm{AC}(\mathrm{P}<0.0001)$ (Figure $2 \mathrm{~B})$. In addition, C-Met expression was found in stromal cells from AC $(2.3 \%)$ and lip SCC lesions (50.3\%) (not shown).

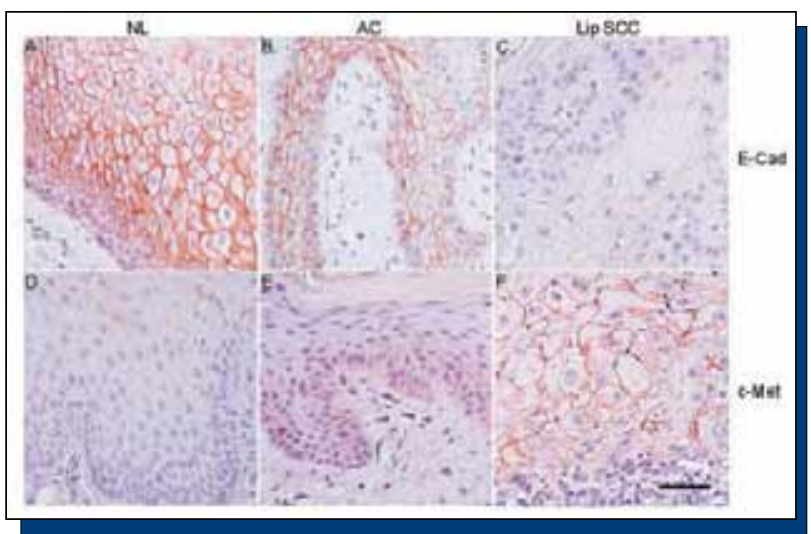

Figure 1. Immunohistochemical detection of E-cadherin and c-Met in normal lip (NL), actinic cheilits (AC) and lip SCC. (A-C) Representative microphotographs of epithelial E-Cadherin (E-Cad) expression in NL (A), AC (B), and lip SCC (C) sections. (D-F) Representative microphotographs of epithelial C-Met expression in NL (D), AC (E), and lip SCC (F) sections. Bar represents 50um.

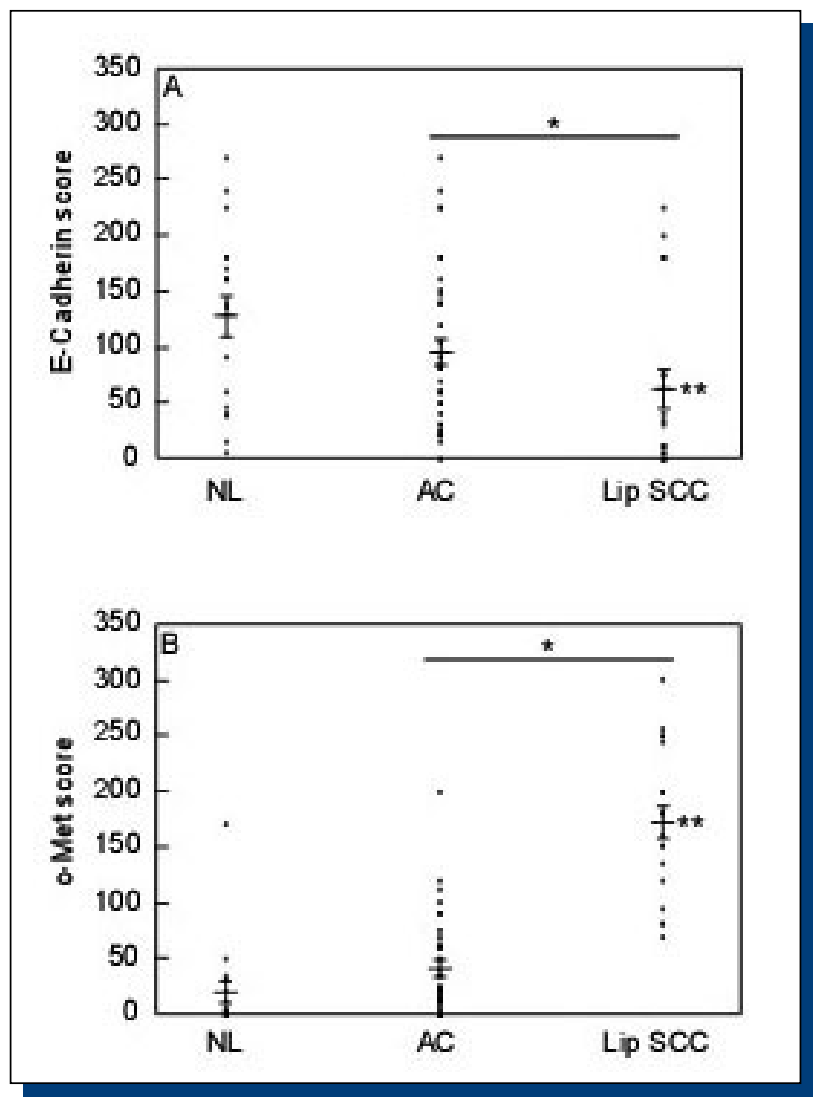

Figure 2. Expression score for E-cadherin and c-MET in normal lip (NL), actinic cheilitis (AC), and lip SCC. A combined expression score of staining intensity and extension was obtained for $\mathrm{E}$ - Cadherin (A) and C-Met (B) from each sample.

${ }^{*} \mathrm{P}<0.05$ (Mann-Whitney test), for E-cadherin and c-Met expression in AC and lip SCC as compared to $\mathrm{NL}$. ${ }^{* *} \mathrm{P}<0.001$ for E-cadherin and $\mathrm{C}-$ Met expression in $\mathrm{AC}$ as compared to lip SCC.

Table 1. Cellular localization of E-cadherin expression in normal lip, actinic cheilitis, and lip SCC

\begin{tabular}{|c|c|c|c|c|c|c|}
\hline \multirow[t]{2}{*}{ E-cadherin } & \multicolumn{2}{|c|}{ Normal Lip } & \multicolumn{2}{|c|}{ Actinic Cheilitis } & \multicolumn{2}{|c|}{ Lip SCC } \\
\hline & $\mathbf{n}$ & $\%$ & $\mathbf{n}$ & $\%$ & $\mathrm{n}$ & $\%$ \\
\hline $\begin{array}{l}\text { Strong } \\
\text { Membranous }\end{array}$ & 18 & 100 & 12 & 33.3 & & \\
\hline $\begin{array}{l}\text { Mild } \\
\text { Membranous }\end{array}$ & & & 21 & 58.4 & 8 & 36.7 \\
\hline $\begin{array}{l}\text { Membranous } \\
\text { ICytoplasmatic }\end{array}$ & & & 3 & 8.3 & 6 & 27.3 \\
\hline Cytoplasmatic & & & & & 1 & 4.2 \\
\hline Loss & & & & & 7 & 31.8 \\
\hline Total & 18 & 100 & 36 & 100 & 22 & \\
\hline
\end{tabular}

Table 2. Cellular localization of c-Met expression in normal lip, actinic cheilitis, and lip SCC.

\begin{tabular}{|l|c|c|c|c|c|c|}
\hline \multirow{2}{*}{ C-Met } & \multicolumn{2}{|c|}{ Normal Lip } & \multicolumn{2}{c|}{ Actinic Cheilitis } & \multicolumn{2}{c|}{ Lip SCC } \\
\cline { 2 - 7 } & $\mathbf{n}$ & $\%$ & $\mathbf{n}$ & $\%$ & $\mathbf{n}$ & $\%$ \\
\hline $\begin{array}{l}\text { No } \\
\text { expression }\end{array}$ & 11 & 61.1 & & & & \\
\hline $\begin{array}{l}\text { Mild } \\
\text { Membranous }\end{array}$ & 7 & 38.9 & & & & \\
\hline $\begin{array}{l}\text { Membranous } \\
\text { ICytoplasmatic }\end{array}$ & & & 2 & 5.5 & & \\
\hline Cytoplasmatic & & & 34 & 94 & 22 & 100 \\
\hline Total & $\mathbf{1 8}$ & $\mathbf{1 0 0}$ & $\mathbf{3 6}$ & $\mathbf{1 0 0}$ & $\mathbf{2 2}$ & \\
\hline
\end{tabular}




\section{DISCUSSION}

E-cadherin and its associated intracellular catenins are a key cell-cell adhesion protein in epithelial cells ${ }^{(3)}$. The loss of E-cadherin expression and/or function reduces cell-cell contacts and has been correlated with enhanced tumor progression and invasion ${ }^{(12,16)}$. E-cadherin inactivation may also occur early in some premalignant lesions, and the loss of expression is thought to induce intracellular signaling that promotes tumor development and progression $(5,10,13)$.

The present study showed that the progression of actinic cheilitis, a premalignant lesion caused by chronic exposure to UV radiation, to lip SCC is closely associated with a significant reduction or loss of E-cadherin expression. The expression of E-cadherin was significantly decreased in lip SCC as compared to $A C$ and normal lip. The data also showed that E-cadherin was significantly decreased in AC compared with normal lip. This is in agreement with other studies that found elevated expression of E-cadherin in normal oral epithelium ${ }^{(4,11)}$, but weaker staining for E-cadherin in the dysplastic areas ${ }^{(5,6,6,9,1)}$ as well as the infiltrating neoplastic islands of the invasive SCC carcinoma $^{(5-7,9,11,12)}$.

Previously, we reported a significant increase in MDM-2 epithelial expression in AC compared to normal lip ${ }^{(26)}$. The use of immunohistochemical methods in breast cancer has led to lower levels of E-cadherin associated with higher expression of MDM-2(27). Yang et al. ${ }^{(27)}$ identified E-cadherin as a new substrate for MDM-2, demonstrating that MDM2 ubiquitinates E-cadherin and decreases its protein levels.

On the other hand, reduction or loss of E-cadherin expression together with increased COX-2 expression has been reported previously in HCA-7 colon carcinoma cells ${ }^{(28)}$, in non-small cell lung cancer ${ }^{(16)}$, and in prostate cancer ${ }^{(17)}$.

It has been demonstrated that COX-2 overexpression is a crucial event in the initial stage of UV-induced skin cancer ${ }^{(29)}$. Our previous study found that in early lip carcinogenesis, COX-2 protein and mRNA expression increased in $\mathrm{AC}^{(30)}$. Brouxhon et al. ${ }^{(6)}$ using chronically UV-irradiated SKH-1 mice, showed a sequential loss of E-cadherin from dysplasia to SCCs; those authors also demonstrated that E-cadherin levels declined at the same time PG2 synthesis was enhanced.

In several neoplasias, c-Met expression has been elevated in the tumor as well as in endothelial and inflammatory cells ${ }^{(7,15,19,20,22,23)}$. These findings are corroborated in this study because the expression of c-Met increased significantly as lip carcinogenesis progressed. The result showed that in the early and later stages of lip carcinogenesis, c-Met expression was significantly increased in lip SCC as compared with the epithelium of AC lesions and normal lip. In addition, increased c-Met expression was found in stromal cells of lip SCC.

Other studies from this group have shown that p53 epithelial expression is significantly increased in actinic cheilitis as compared to normal lip(26,31). Induction of p53 by UV irradiation in RKO cells that express wild-type p53 increases the level of endogenous c-Met gene product. Seol et al. ${ }^{(32)}$ demonstrated that c-Met is induced by UV light and that $\mathrm{p} 53$ plays a role in this activation process.
Conversely, HGF is well-known to be secreted by fibroblasts surrounding the tumor, helping cancer cells invade the all-around stroma $^{(23,34)}$. Chen et al. ${ }^{(23)}$ observed that in oral SCC, parenchymal cells expressed high amounts of HGF and c-Met, as did stromal fibroblasts, endothelial cells, and inflammatory cells. Therefore, cancer cells are being stimulated to proliferate by autocrine and paracrine mechanisms. In the present study, we found that c-Met was expressed by stromal cells, some fibroblasts, endothelial cells, and inflammatory cells in AC (2.3\%) samples and in lip SCC (50.3\%).

It has been shown that HGF regulates the expression of COX-2 and increases synthesis of prostaglandins (PG) in gastric mucosal cells. Overexpression of COX-2 and increased PG secretion are involved in the regulation and growth of gastric cancer. Chen et al. ${ }^{(21)}$ found 30 cases of gastric cancer overexpression of c-Met (93.3\%) and COX-2 (53.3\%). The expression of c-Met was positively correlated with COX-2 $(r=0.41$, $\mathrm{P}=0.024)$. Scarpino et al. ${ }^{(24)}$ suggest that the increased expression of c-Met protein in thyroid papillary carcinoma played a role in up-regulating the expression of COX-2, which, in turn, contributes to the invasive capacity.

Taken together, the reduction or loss of E-cadherin expression with increased c-Met expression in AC and lip SCC shown in our data agree with other studies that have demonstrated that the activation of C-Met by HGF is associated with decreased E-cadherin ${ }^{(7,13,18,33,34)}$. Murai et al. ${ }^{(7)}$ found a significant increase of c-Met expression in oral SCC as well as in dysplastic epithelium adjacent to tumor, and they suggest that the overexpression of c-Met interacts with E-cadherin to facilitate the disruption of intercellular junctions, thereby promoting invasion and metastasis. Shimabukuro et al. ${ }^{\left({ }^{34}\right)}$ reported that HGF produced by stromal cells influences the mode of stromal invasion of uterine squamous cervical cancer by decreasing E-cadherin.

In summary, the results showed that epithelial E-cadherin expression is reduced and c-Met expression is increased as lip carcinogenesis progresses (normal lip>AC>lip SCC), suggesting that these could be useful markers of malignant transformations in the lip. Future research should be performed to demonstrate the correlation of COX-2, c-Met, and E-cadherin in photodamaged lip.

\section{CONFLICT OF INTEREST STATEMENT}

None declared.

\section{ACKNOWLEDGMENTS}

Supported by the Chilean Council of Science and Technology (CONICYT), grant FONDECYT 1090287, and University of Concepción Research Foundation, grant DIUC 208.103.018-1.0.

\section{REFERENCES}

1. de Visscher JG, van der Waa. Etiology of the cancer of the lip. A review. Int J Oral Maxillofac Surg, 1998; 27: 199-203.

2. Takeichi M. Cadherins: A molecular family important in cell-cell adhesion. Ann Rev Biochem, 1990; 59: 237-252.

3. Shiozaki H, Oka H, Inoue M, Tamura S, Monden M. E-cadherin mediated adhesion system in cancer cells. Cancer, 1996; 77: 1605-1613.

4. Sakaki T, Tamura I, Kadota H, Kakudo K. Changing expression of E- and $\mathrm{P}$ - cadherin during the tongue carcinogenesis induced by 4-itroquinoline 1-oxide. J Oral Pathol Med, 2003; 32: 530-537.

5. Santos-Garcia A, Abad-Hernández MM, Fonseca-Sánchez E, JuliánGonzález R, Galindo-Villardón P, Cruz-Hernández JJ, Bullón-Sopelana A. E-cadherin, laminin and collagen IV expression in the evolution from dysplasia to oral squamous cell carcinoma. Med Oral Patol Oral Cir Bucal, 2006; 1: 11(2): E100-105.

6. Brouxhon S, Kyrkanides S, O'Banion MK, Johnson R, Pearce DA, Centola GM, Miller JH, McGrath KH, Erdle B, Scott G, Schneider S, Van Buskirk JA, Pentland AP. Sequential down-regulation of E-Cadherin with squamous cell carcinoma progression: Loss of E-Cadherin via a prostaglandin E2-EP2-dependent posttranslational mechanism. Cancer Res, 2007; 67: 7654-7664.

7. Murai M, Shen X, Huang L, Carpenter W.M, Lin C.S, Silverman S, Regezi J, Kramer RH. Overexpression of c-met in oral SCC promotes hepatocyte growth factor-induced disruption of cadherin junctions and invasion. International Journal of Oncology, 2004; 25: 831-840.

8. Koseki S, Ansai S, Aoki T, Hozumi Y, Mitsuhashi Y, Kondo S. E-cadherin expression in skin tumors using an AMeX immunohistostaining method. $J$ Dermat, 2000; 27: 307-311.

9. Bánkfalvi A, Krabort M, Vegh A, Felszeghy E, Piffko J. Deranged expression of the E-cadherin/ß -catenin complex and the epidermal growth factor receptor in the clinical evolution and progression of oral squamous cell carcinomas. J Oral Pathol Med, 2002; 31: 450-457.

10. Dinitz-Freitas M,Garcia-Caballero T, Antúnez-López J, Gándara-Rey JM, Garcia-Garcia A. Reduced E-cadherin expression as an indicator of unfavorable prognosis in oral squamous cell carcinoma. Oral Oncol, 2006; 42: 190-120.

11. Hung KF, Chang CS, Liu CJ, Lui MT, Cheng CY, Kao SY. Differential expression of E-cadherin in metastatic lesions comparing to primary oral squamous cell carcinoma. Oral Pathol Med, 2006; 35: 589-594.

12. Cruz MC, Pereira AL, Lopes FF, Nonaka CF, Silva RR, Freitas Rde A Souza LB, Pinto LP. Immunohistochemical expression of E-cadherin and CD44v6 in squamous cell carcinomas of the lower lip and tongue. Braz Dent J, 2009; 20: 64-69.

13. Han SU, Lee HY, Lee JH, Kim WH, Nam H, Kim H, Cho YK, Kim MW, Lee KU. Modulation of E-cadherin by hepatocyte growth factor induces 
aggressiveness of gastric carcinoma. Ann Surg, 2005; 242: 676-683. 14. Yong-Quan Chu, Zai-Yuan Ye, Hou-Quan Tao, Yuan-Yu Wang, ZhongSheng Zhao. Relationship between cell adhesion molecules expression and the biological behavior of gastric carcinoma. World J Gastroenterol, 2008; 14: 1990-1996.

15. Götte M, Kersting C, Radke I, Kiesel L, Wülfing P. An expression signature of syndecan-1 (CD138), E-cadherin and c-met is associated with factors of angiogenesis and lymphangiogenesis in ductal breast carcinoma in situ. Breast Cancer Res, 2007; 9: 1-12.

16. Dohadwala M, Yang SC, Luo J, Sharma S, Batra RK, Huang M, Lin Y, Goodglick L, Krysan K, Fishbein MC, Hong L, Lai C, Cameron RB, Gemmill RM, Drabkin HA, Dubinett SM. Cyclooxygenase-2-dependent regulation of E-cadherin: Prostaglandin $E(2)$ induces transcriptional repressors ZEB1 and snail in non-small cell lung cancer. Cancer Res, 2006; 15; 66: 5338-5345.

17. Rao DS, Gui D, Koski ME, Popoviciu LM, Wang H, Reiter RE, Said JW. An inverse relation between COX-2 and E-cadherin expression correlates with aggressive histologic features in prostate cancer. Appl Immunohistochem Mol Morphol, 2006; 14: 375-383.

18. Kim CH, Kim J, Kahng $\mathrm{H}$, Choi EC. Change of E-cadherin by hepatocyte growth factor and effects on the prognosis of hypopharyngeal carcinoma. Ann Surg Oncol, 2007; 14: 1565-1574.

19. Moon WS, Park HS, Lee H, Pai R, Tarnawski AS, Kim KR, Jang KY Co-Expression of COX-2, C-Met and B-catenin in cells forming invasive of gallbladder cancer. Cancer Res Treat, 2005; 37: 171-176.

20. Drebber U, Baldus SE, Nolden B, Grass G, Bollschweiler E, Dienes HP, Hölscher AH, Mönig SP. The over expression of c-met as a prognostic indicator for gastric carcinoma compared to p53 and p21 nuclear accumulation. Oncol Rep, 2008; 19: 1477-1483.

21. Chen JH, Wu CW, Kao HL, Chang HM, Li AF, Liu TY, Chi CW. Effects of COX-2 inhibitor on growth of human gastric cancer cells and its relation to hepatocyte growth factor. Cancer Lett, 2006; 239: 263-270.

22. Miyata Y, Sagara Y, Kanda S, Hayashi T, Kanetake H. Phosphorylated hepatocyte growth factor receptor/c-Met is associated with tumor growth and prognosis in patients with bladder cancer: Correlation with matrix metalloproteinase -2 and -7 and E-cadherin. Hum Pathol, 2009; 40: 496504.

23. Chen YS, Wang JT, Chang YF, Liu BY, Wang YP, Sun A, Chiang CP. Expression of hepatocyte growth factors and c-met protein is significantly associated with the progression of oral squamous cell carcinoma in Taiwan. J Oral Pathol Med, 2004; 33: 209-217.
24. Scarpino S, Duranti E, Stoppacciaro A, Pilozzi E, Natoli G, Sciacchitano S, Luciani E, Ruco L. COX-2 is induced by HGF stimulation in Met-positive thyroid papillary carcinoma cells and is involved in tumour invasiveness. J Pathol, 2009; 218: 487-494.

25. Wislez M, Spencer ML, Izzo JG et al. Inhibition of mammalian target of rampamycin reverses alveolar epithelial neoplasia induced by oncogenic K-ras. Cancer Res, 2005; 65: 3226-3235.

26. Martínez A, Brethauer U, Borlando J, Spencer ML, Rojas IG. Epithelial expression of p53, mdm-2 and p21 in normal lip and actinic cheilitis. Oral Oncol, 2008; 44: 878-883.

27. Yang JY, Zong CS, Xia W, Wei Y, Seyed MA, Zheng Li, Broglio K, Berry DA, Hung M CH. MDM2 Promotes cell motility and invasiveness by regulating E-cadherin degradation. Molecular and Cellular Biology, 2006; 26(19): 7269-7282.

28. Chang YW, Marlin JW, Chance TW, Jakobi R. RhoA mediates cyclooxygenase-2 signaling to disrupt the formation of adherens junctions and increase cell motility. Cancer Res, 2006; 15:66: 11700-11708.

29. Bowden GT. Prevention of non-melanoma skin cancer by targeting ultraviolet-B-light signaling. Nat Rev Cancer, 2004; 4: 23-35.

30. Rojas IG, Martínez A, Brethauer U, Grez P, Yefi R, Luza S, Marchesani FJ. Actinic cheilitis: Epithelial expression of COX-2 and its association with mast cell tryptase and PAR-2. Oral Oncol, 2009; 45: 284-290.

31. Martínez A, Brethauer U, Rojas IG, Spencer M, Mucientes F, Borlando $\mathrm{J}$, Rudolph MI. Expression of apoptotic and cell proliferation regulatory proteins in actinic cheilitis. J Oral Pathol Med, 2005; 34: 257-262.

32. Seol DW, Chen Q, Smith ML, Zarnegar R. Regulation of the c-met proto-oncogen promoter by p53. The Journal of Biological Chemistry, 1999; 274: 3565-3572.

33. Reshetnikova G, Troyanovsky S, Rimm DL. Definition of a direct extracellular interaction between Met and E-cadherin. Cell Biol Int, 2007; 31: $366-373$

34. Shimabukuro K, Ichinose $\mathrm{S}$, Koike $\mathrm{R}$, Kubota $\mathrm{T}$, Yamaguchi $\mathrm{M}$ Miyasaka M, Aso T. Hepatocyte growth factor/scatter factor is implicated in the mode of stromal invasion of uterine squamous cervical cancer. Gynecol Onco, 2001; 83: 205-215. 